\title{
Institucionalização de novas práticas de controles de gestão: forças que potencializam ou comprometem o processo nos pequenos empreendimentos
}

Institutionalization of new management control practices: forces that potentiate or limit the process in small companies

Institucionalización de nuevas prácticas de controles de gestión: fuerzas que potencian o comprometen el proceso en los pequeños emprendimientos

\section{Maria Elena Amaral Ferreira Bueno}

Mestre em Administração pela Universidade de Passo Fundo (UPF)

Professora na Faculdade de Ciências Econômicas Administrativas e Contábeis da Universidade de Passo Fundo (UPF)

Endereço: Rod. BR 285, KM 292,7 - Campus I Bairro São José

CEP: 99052-900 - Passo Fundo/RS - Brasil

E-mail: abueno@upf.br

Telefone: (54) 3316-8100

\section{Rodrigo Angonese}

Doutor em Ciências Contábeis e Administração pela Universidade Regional de Blumenau (FURB)

Professor no Programa de Pós-graduação em Administração da Universidade de Passo Fundo (UPF)

Endereço: Rod. BR 285, KM 292,7 - Campus I Bairro São José

CEP: 99052-900 - Passo Fundo/RS - Brasil

E-mail: rangonese@gmail.com

Telefone: (54) 33168100

\section{Débora Gomes de Gomes}

Doutora em Ciências Contábeis e Administração pela Universidade Regional de Blumenau (FURB)

Professora no Programa de Pós-Graduação em Ciências Contábeis da Universidade Federal do Rio Grande (FURG)

Endereço: Rua Karlo Harazin, 71, Vila São Jorge

CEP: 96.203-210 - Rio Grande/ RS - Brasil

E-mail: debora_furg@yahoo.com.br

Telefone: (53) 98144-9000

Artigo recebido em 25/07/2019. Revisado por pares em 27/09/2019. Reformulado em 09/04/2020. Recomendado para publicação em 15/04/2020 por Carlos Eduardo Facin Lavarda (Editor-Chefe). Publicado em 24/04/2020. 


\section{Resumo}

Este estudo objetiva analisar as forças que potencializam e/ou comprometem o processo de institucionalização de novas práticas de controles de gestão em pequenos empreendimentos. Tratase de estudo de caso múltiplo, descritivo, qualitativo, realizado com base na teoria institucional e no modelo de Tolbert e Zucker (1999). Transcrição das entrevistas, análise documental e observação foram submetidos à análise de conteúdo com auxílio do software Atlas.ti 8.0®. Os resultados revelaram que, além das pressões externas decorrentes do mercado e legislações específicas, houve a presença do poder hierárquico impulsionando a mudança. Porém, fatores de resistência interna podem comprometer o processo. Das empresas estudadas, uma conseguiu superar a resistência inicial e implementou a mudança, enquanto outra precisou interromper o processo. Deduz-se que os fatores que potencializam e/ou comprometem a mudança possuem intensidade diferenciada, variando conforme o contexto organizacional. Gerenciar fatores internos de forma holística pode contribuir para sanar possíveis resistências de forma preventiva.

Palavras-chave: Teoria institucional; Controles de gestão; Mudança

\section{Abstract}

This study aims to analyze the forces that potentiate or limit the process of institutionalization of new management control practices in small companies. It was adopted a multiple, descriptive, qualitative case study, carried out through institutional theory and the model of Tolbert and Zucker (1999). Transcription interviews, documentation and observation were analyzed through content analysis using software Atlas.ti $8.0 \circledR$. The results revealed that, in addition to the external pressures arising from the market and specific legislation, there was the presence of hierarchical power driving change. Internal resistance factors may limit the process. Of the companies studied, one managed to overcome the initial resistance and implemented the change, while another had to stop the process. It is deduced that the factors that potentiate or limit the change have different intensity, varying according to the organizational context. Managing internal factors in a holistic way can help prevent possible resistance in a preventive way.

Keywords: Institutional theory; Management controls; Change

\section{Resumen}

Este estudio objetivó analizar las fuerzas que potencian o comprometen el proceso de institucionalización de nuevas prácticas de controles de gestión en pequeños emprendimientos. Un estudio de caso múltiple, descriptivo, cualitativo, realizado por medio de la teoría institucional y del modelo de Tolbert y Zucker (1999). Transcripción de entrevistas, documentación y observación se analizaron a través del análisis de contenido y utilizando software Atlas.ti 8.0®. Los resultados revelaron presiones externas del mercado y legislaciones, y el poder jerárquico interno impulsando el cambio. Sin embargo, la resistencia interna puede comprometer el proceso. De las empresas estudiadas, una superó la resistencia e implementó el cambio, mientras que otra interrumpió el proceso. Se deduce que los factores que potencian o comprometen el cambio tienen una intensidad diferenciada, variando según el contexto organizacional. La gestión de factores internos de forma holística puede contribuir a remediar posibles resistencias de forma preventiva. Palabras clave: Teoría institucional; Controles de gestión; Cambio

\section{Introdução}

A inovação nos processos de gestão é fundamental para operar em ambientes complexos (BURNS; EZZAMEL; SCAPENS, 2003; ZONI; DOSSI; MORELLI, 2012). Inovação remete à mudança. Neste estudo, o processo de mudança está relacionado a implementação de novas práticas de controle gerencial. 
Existem várias abordagens teóricas para o estudo da mudança organizacional na contabilidade gerencial. Dentre elas destaca-se a Teoria Institucional, que abrange um conjunto de construtos teóricos provenientes da economia, da sociologia e da ciência política (SCAPENS, 1994; MACHADO-DA-SILVA; GONÇALVES, 1999; GUERREIRO et al., 2005; GUERREIRO; FREZATTI; CASADO, 2006). Segundo Burns e Scapens (2000), ela é classificada em três vertentes que, embora tenham diferentes origens e raízes filosóficas, partilham um interesse comum por temas como instituição e mudança institucional (BURNS; SCAPENS, 2000; GUERREIRO et al., 2005; LIGUORI; STECCOLINI, 2012).

Neste estudo optou-se pela vertente da Nova Sociologia Institucional (NSI). Na NSI o processo de mudança pode ser concebido por uma visão macro, referente ao ambiente no qual a organização está inserida e nas pressões que ele pode exercer para a adoção de determinadas práticas de controle gerencial (MEYER; ROWAN, 1977; DIMAGGIO; POWELL, 1983; RIBEIRO; SCAPENS, 2006). Nesta pesquisa, a institucionalização de novas práticas é abordada por meio do modelo de Tolbert e Zucker (1999) que considera as variáveis do ambiente social externo, especialmente as mudanças tecnológicas, legislação e forças de mercado. Por presumir que uma organização está inserida em um contexto social abrangente, o processo de institucionalização proposto pelas autoras considera fatores externos e internos como responsáveis pela institucionalização (RUSSO; PARISI; PEREIRA, 2016).

O processo de mudança, nesta pesquisa, envolve a implementação do Sistema de Gestão da Qualidade (SGQ) em duas empresas industriais de pequeno porte. Em relação às práticas de controle gerencial, Guerreiro, Cornachione Júnior e Soutes (2011, p. 90) os definem como "modelos de gestão, sistemas de gestão, sistemas de informação e conceitos de avaliação de desempenho". Dessa forma, a adoção do SGQ pode ser considerada uma decisão estratégica para a organização. Afinal, pode contribuir na melhoria de seu desempenho global além de fornecer subsídios para ações voltadas ao desenvolvimento sustentável (ABNT, 2015).

A ISO 9001, criada pela International Organization for Standardization (ISO), constitui "uma série de normas sobre gestão da qualidade que pode ser aplicada a empresa, produtos e serviços, contribuindo para a revolução de seus sistemas de gestão da qualidade, auxiliando as empresas a aumentar sua eficiência e a satisfação do cliente" (ABNT, 2015 p.14). Ampliar mercados, melhorar o nível de organização interna, aumentar o controle da administração e da produtividade, além de contribuir para a redução de custos e diminuição do número de erros, são fatores que proporcionam a credibilidade junto ao mercado, favorecendo os pequenos negócios (ABNT, 2015).

No que diz respeito à micro e pequenas empresas, sabe-se que exercem um papel importante na economia brasileira, destacando-se na geração de empregos e na distribuição de renda. Segundo dados do Cadastro Central de Empresas 2015 do Instituto Brasileiro de Geografia e Estatística - IBGE (2017), a maioria das empresas ativas se enquadra na faixa de pequenos empreendimentos. Mesmo com estas evidências, as pesquisas brasileiras direcionadas a este porte de empresas, especialmente quanto às práticas gerenciais e sua institucionalização, ainda são incipientes (NASCIMENTO; JUNQUEIRA; MARTINS, 2010; KOS et al., 2014; FREZATTI et al., 2015; SANTOS; DOROW; BEUREN, 2016; PAULO; CINTRA, 2018). O foco das pesquisas nacionais sobre práticas gerenciais esteve mais voltado para médias e grandes empresas, a exemplo de Frezatti (2005); Oyadomari et al. (2008a); Guerreiro, Cornachione Júnior e Soutes (2011); Frezatti et al. (2012). O mesmo foi comprovado por Hopper e Bui (2016) que investigaram os primeiros 25 anos de publicações da Management Accounting Research e constataram que, a maioria das pesquisas está direcionada aos grandes empreendimentos.

Diante deste contexto e visando contribuir com a pesquisa sobre o processo de mudança nos controles de gestão, a questão que norteia esta pesquisa é: quais as forças que potencializam ou comprometem o processo de institucionalização de novas práticas de controle de gestão em pequenos empreendimentos? 
Assim, o objetivo deste estudo é analisar as forças que potencializam ou comprometem o processo de institucionalização de novas práticas de controle de gestão em empreendimentos de pequeno porte, sendo estudado com base na NSI e no modelo de Tolbert e Zucker (1999). O pressuposto da pesquisa empreende que as forças presentes no processo de implementação do sistema de gestão da qualidade decorrem das diferentes instituições internas e externas, presentes no modelo de Tolbert e Zucker (1999).

Pesquisas que buscam compreender os motivos que levam os processos relacionados a novas práticas de contabilidade gerencial, serem ou não incorporados à rotina dos pequenos empreendimentos, ainda recebem pouca atenção (FREZATTI et al., 2015; SANTOS; DOROW; BEUREN, 2016; LUZ et al., 2018). Dessa forma, investigar o porquê da institucionalização de práticas gerenciais serem bem sucedidas ou não, em pequenos empreendimentos, requer maior aprofundamento.

Esta pesquisa contribui com novas discussões sobre a base teórica apresentada por Tolbert e Zucker (1999). Com base em um estudo de caso múltiplo e descritivo, busca evidenciar forças externas e internas que podem estar presentes durante todo o processo de mudança e não apenas em estágios específicos, como proposto no modelo estudado. Além disso, busca subsídios para confirmar resultados de estudos anteriores.

Quanto à contribuição empírica desta pesquisa, entender como ocorre o processo de mudança nessas organizações pode colaborar com a eficiência em sua implementação, uma vez que auxilia no entendimento de quais forças podem potencializar o processo. Da mesma forma, pode fornecer subsídios para sanar possíveis resistências de forma preventiva, otimizando tempo e recursos. Essa contribuição talvez consiga auxiliar na institucionalização de controles gerenciais, tão importantes para a gestão dos pequenos empreendimentos.

\section{Referencial Teórico}

\subsection{Teoria Institucional e o processo de institucionalização de práticas de controle gerencial}

A teoria institucional é o reflexo das transformações ocorridas na área dos estudos organizacionais a partir de meados dos anos 60, quando os trabalhos passaram a ser orientados pela perspectiva de sistemas abertos (SCOTT, 1995; 2001). Porém, diferindo dos estudos clássicos em organizações em relação a forma como é contemplada a noção de ambiente, uma vez que a atenção se volta para a relação de influência recíproca entre organizações e campos organizacionais de um lado, estruturas normativas e culturais mais amplas de outro (SCOTT, 1995; GUARIDO FILHO, MACHADO-DA-SILVA; GONÇALVES, 2009). A Teoria Institucional está relacionada à criação, adoção, adaptação e difusão de estruturas, bem como a esquemas, regras, normas e rotinas ao longo do tempo (SCOTT, 2005).

Em relação à contabilidade gerencial, a teoria institucional a considera como uma instituição dentro da empresa, ou seja, uma rotina formada por hábitos e aceita de forma inquestionável, dando sentido a um grupo de pessoas (BURNS; SCAPENS, 2000; PEREIRA; GUERREIRO, 2005; GUERREIRO; PEREIRA; FREZATTI, 2008). Dessa forma, a mudança nos controles gerenciais ocorre quando novas práticas são transformadas em hábitos e rotinas amplamente aceitas na organização (SCAPENS, 1994, BURNS; SCAPENS, 2000; GUERREIRO et al., 2005). Essa mudança constitui um processo contínuo, devendo considerar as perspectivas dos vários grupos da organização (SCAPENS, 2006).

Burns e Scapens (2000) classificam a teoria institucional em três vertentes: Velha Economia Institucional (VEI), Nova Economia Institucional (NEI) e Nova Sociologia Institucional (NSI), sendo esta última a vertente adotada neste estudo. A NSI surgiu em oposição à perspectiva positivista, sendo considerada predominante no campo da sociologia (MOLL; BURNS; MAJOR, 
2006). Focaliza sua atenção nas instituições externas ao ambiente organizacional, que influenciam as estruturas e os sistemas organizacionais (SCAPENS, 2006).

Neste sentido, a NSI estuda como o ambiente institucional, formado de normas, crenças, tradições e busca por legitimidade, afeta o comportamento das organizações (DIMAGGIO; POWELL, 1983; OYADOMARI et al., 2008a; FREZATTI et al., 2009). Parte do pressuposto de que as organizações sofrem pressões do ambiente no qual estão inseridas, em virtude da aceitação de procedimentos socialmente institucionalizados, que proporcionariam à organização legitimação externa e vantagens imprescindíveis para a obtenção de recursos necessários à sobrevivência (MEYER; ROWAN, 1977; COVALESKI et al., 2007; OYADOMARI et al., 2008a; FREZATTI et al., 2009). Pesquisadores têm utilizado a NSI para estudar a estabilidade e os processos de mudança nas práticas de controles de gestão (BURNS; SCAPENS, 2000; OYADOMARI et al., 2008a).

Dessa forma, a teoria institucional possui uma perspectiva sociológica, considerando a construção social da realidade (BERGER; LUCKMANN, 1976), contribuindo para a gestão das organizações, pois busca explicar os fenômenos organizacionais por meio da compreensão de como as estruturas e ações organizacionais tornam-se legitimadas (DIMAGGIO; POWELL, 1983), levando em conta que os processos resultam não apenas da ação humana, mas do contexto em que se situam (COVALESKI; DIRSMITH; SAMUEL, 1996).

$\mathrm{Na}$ teoria institucional, um dos conceitos predominantes é a institucionalização. A institucionalização se refere ao processo pelo qual componentes de uma estrutura formal são largamente aceitos como apropriados e necessários (TOLBERT; ZUCKER, 1999). A legitimação ocorre pelo compartilhamento dos sentidos e significados pelos atores (SCOTT, 2001) e a partir daquilo que é amplamente aceito pela sociedade (DIMAGGIO; POWELL, 1983; TOLBERT; ZUCKER, 1999; SCOTT, 2001).

Neste sentido, Tolbert e Zucker (1999) desenvolveram um modelo que envolve quatro fases distintas do processo de institucionalização: inovação, habitualização, objetificação e sedimentação. A Figura 1 mostra o modelo proposto pelas autoras, porém com a divisão entre os três estágios sugeridos por elas.

Para as autoras, o processo de institucionalização ocorre em três estágios distintos: préinstitucional, semi-institucional e total institucionalização. No estágio pré-institucional estão as forças causais exógenas à organização, geralmente derivadas de mudanças de tecnologias, de legislações e das forças de mercado, que podem levar à introdução de inovações nas organizações e incentivar a criação de novos hábitos (TOLBERT; ZUCKER, 1999). Scott (2001) ressalta a importância em identificar forças que pressionam a institucionalização de determinados processos, tais como grupos de interesse e parceiros estratégicos, entre outros. Alguns estímulos não são oriundos exclusivamente de forças externas, pois as organizações competem ainda por poder político e legitimidade institucional, tanto para o bem social como econômico (DIMAGGIO; POWELL, 1983).

Ainda no estágio de pré-institucionalização, na fase da habitualização, a adoção das práticas leva em consideração soluções desenvolvidas por outras organizações que estão vivenciando o mesmo tipo de problema. Os comportamentos são organizados e formalizados como arranjos estruturais, concebidos em resposta a problemas organizacionais específicos, sem despender grandes esforços ou investimentos (TOLBERT; ZUCKER, 1999). Nesta fase de habitualização, portanto, os estímulos são percebidos por diversos agentes dentro das organizações e cada um responde a esses estímulos, propondo soluções. Assim, existe a inovação pela troca de conhecimentos, com a participação individual ou simultânea dos agentes envolvidos. 
Figura 1 - Processos inerentes à institucionalização segundo Tolbert e Zucker (1999)

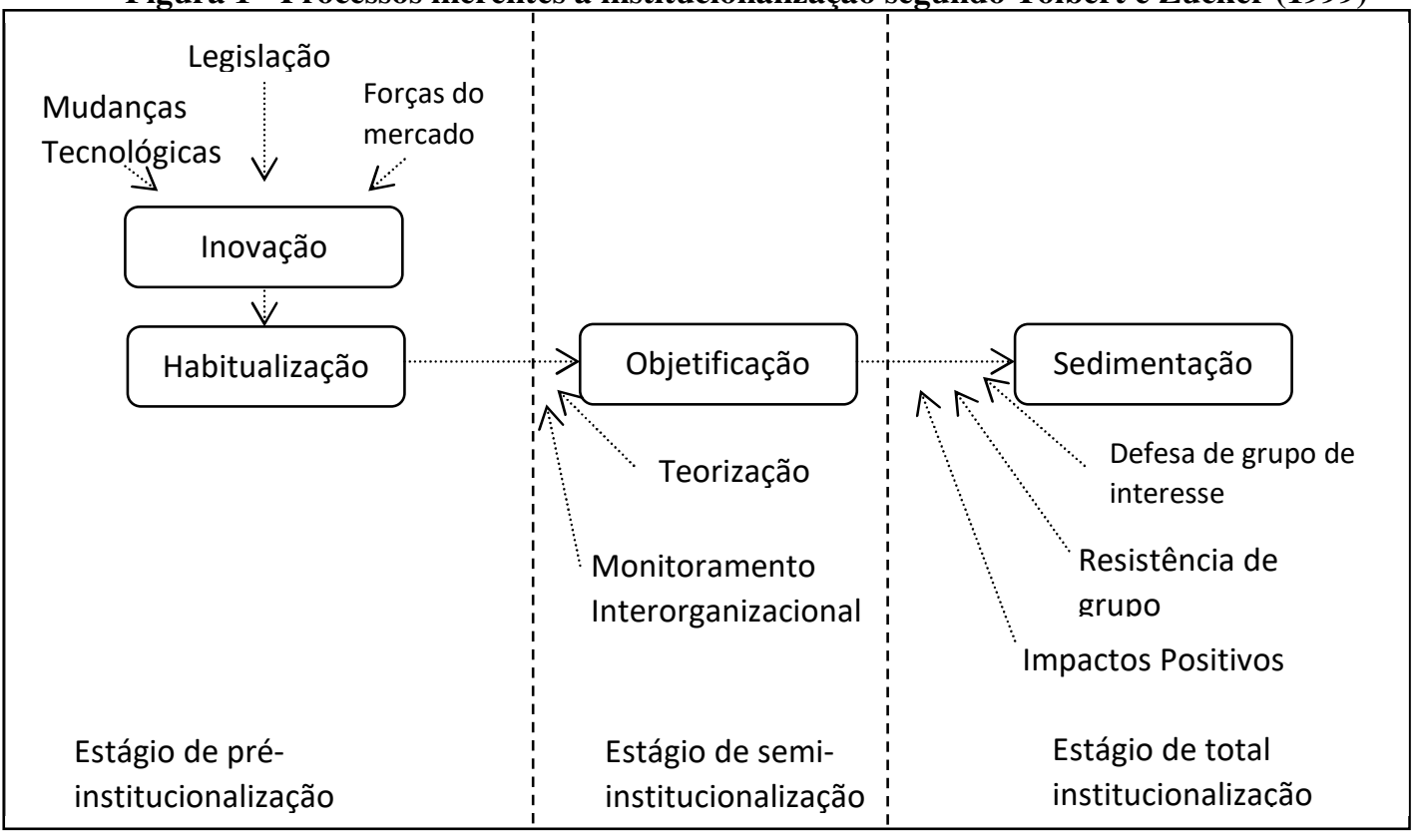

Fonte: Adaptado de Tolbert e Zucker (1999, p. 207)

A partir dessa fase, portanto, o modelo evidencia o monitoramento interorganizacional, que diz respeito à troca de conhecimentos entre as organizações, na busca de uma solução para um determinado problema comum. A formalização dessa inovação envolve a teorização dos procedimentos adotados ou dos arranjos estruturais (TOLBERT; ZUCKER, 1999). Para assegurar a viabilização da objetificação, o monitoramento interorganizacional e a teorização são elementos fundamentais.

O estágio da semi-institucionalização trata da objetificação do novo elemento institucional. Envolve certo grau de consenso social entre os agentes tomadores de decisões, a respeito do valor deste novo elemento (TOLBERT; ZUCKER, 1999). Para as autoras isso ocorre porque as organizações valem-se de informações dos resultados de outras organizações, obtido a partir de um monitoramento do que ocorre nos concorrentes e dos resultados produzidos internamente pelas novas estruturas. Zucker (1988) afirma que a objetificação é um processo chave da institucionalização, pois marca o desprendimento do significado da ação para o indivíduo. Para as autoras, independentemente de quem desempenhe a ação a partir daquele momento, a ação é generalizada e dá-se o nome de objetificação, adquirida a partir da habitualização.

$\mathrm{Na}$ fase de objetificação as organizações podem utilizar evidências de diversas fontes para avaliar os riscos de adoção da nova estrutura, e podem observar as atitudes dos concorrentes, visando manter sua competitividade bem como mensurar a relação custo versus benefício desta prática (TOLBERT; ZUCKER, 1999). Nesta fase, Tolbert e Zucker (1999) destacam a importância de indivíduos com interesse material na definição das práticas, a exemplo dos consultores de qualidade total que difundem modelos, práticas e usam procedimentos de certificação por meio das normas ISO 9000. Para as autoras, neste estágio a teorização torna-se fundamental, pois auxilia a consulta de organizações aos procedimentos necessários para que a adoção de uma nova estrutura possa ser executada, implementada, bem como quais resultados possam ser esperados, auxiliando, portanto, na disseminação do conhecimento.

A institucionalização se consolida no processo chamado de sedimentação, associado ao estágio de total institucionalização (TOLBERT; ZUCKER, 1999). Ocorre quando a estrutura sobrevive por várias gerações na organização, passando a fazer parte da sua história (BERGER; LUCKMANN, 1976; TOLBERT; ZUCKER, 1999). Nessa fase existem fatores que afetam a abrangência do processo de difusão de uma estrutura e sua conservação no longo prazo, portanto, 
conhecê-los é fundamental para a compreensão da sedimentação, a exemplo da resistência de grupos. Atores afetados adversamente pelas estruturas são capazes de se mobilizarem contra elas (TOLBERT; ZUCKER, 1999). Por outro lado, as autoras argumentam que, a inexistência de oposição direta nem sempre significa ausência de obstáculos, uma vez que a impossibilidade de visualizar resultados palpáveis (impactos positivos) com o uso destas práticas pode afetar a sua difusão, principalmente se seus defensores continuam envolvidos em sua teorização e promoção. E, caso esses resultados não sejam alcançados, pode haver desmotivação e descontinuidade das novas estruturas. Assim, estruturas alternativas, que possam alcançar os mesmos fins, podem levar as organizações a abandonar arranjos antigos, o que vem de encontro ao posicionamento de grupos de interesse defensores da manutenção e propagação das estruturas (TOLBERT; ZUCKER, 1999).

Pelo exposto, percebe-se que a cada estágio do processo estão relacionadas forças externas e internas, capazes de potencializar ou comprometer a institucionalização da nova prática. Conhecer estas forças pode ajudar na compreensão de como novas práticas de gestão podem ser institucionalizadas.

\section{Metodologia}

O campo desta pesquisa envolve duas pequenas empresas localizadas no norte do estado do Rio Grande do Sul. O nome das empresas foi resguardado, visto o sigilo das informações apresentadas. Foram tratadas por Empresa A e Empresa B.

Na possibilidade de escolher casos múltiplos, estes são preferíveis a casos simples, pois existe a oportunidade de continuar a replicar os resultados, considerando diferentes contextos e situações (YIN, 2015). Para o autor, a utilização de casos extremos permite um maior aprendizado com os fenômenos observados, aumentando sua validade externa.

Diante dessas recomendações, foi selecionada uma empresa que implementou o SGQ a fim de verificar quais os fatores que potencializaram a institucionalização, dentre os citados no modelo estudado e uma empresa que não conseguiu, a fim de verificar quais os fatores que comprometeram o processo. As empresas foram escolhidas por conveniência (YIN, 2015), pelo acesso e disponibilidade das informações (EISENHARDT, 1989; FLICK, 2009).

A coleta dos dados ocorreu por meio de entrevistas semiestruturadas, pela análise documental e pela observação não participante. Considerando a recomendação para pesquisas de estudo de caso, foi selecionada uma empresa para compor o estudo de caso piloto (YIN, 2015). A empresa foi escolhida pela acessibilidade, estrutura e porte, não constando nos resultados, porém, proporcionando ajustes, principalmente quanto a definição do roteiro final para a entrevista.

A base teórica serviu de subsídio para a construção do roteiro. As categorias de análise foram definidas com base nos conceitos abordados na literatura citada e foi possível identificar as subcategorias de análise representativas dos fatores que potencializam ou comprometem o processo de mudança nos controles de gestão.

As categorias e subcategorias de análise foram identificadas com o auxílio de tabelas sugeridas por Webster e Watson (2002) para a revisão de literatura centrada no conceito. O Quadro 1 apresenta o constructo da pesquisa.

Os sujeitos da pesquisa foram profissionais que atuam no nível gerencial da empresa, bem como o proprietário das organizações. Destaca-se que o nível gerencial, em função do porte empresarial, está diretamente envolvido com a operacionalização das práticas de gestão. Portanto, o nível operacional não participou da pesquisa.

Os entrevistados foram denominados de EA1, EA2 e EA3 na empresa A e EB1, EB2 e EB3 na empresa B. A participação dos entrevistados foi formalizada por meio da assinatura do Termo de Consentimento Livre e Esclarecido (TCLE). Para garantir a confiabilidade dos dados, foi solicitada autorização para gravar as entrevistas. Após realizada a entrevista, o conteúdo da gravação foi transcrito e enviada via correio eletrônico ao entrevistado para sua validação. Todo o 
procedimento da pesquisa foi apresentado aos responsáveis pelas empresas no protocolo de estudo de caso.

Quadro 1 - Constructo da pesquisa

\begin{tabular}{|c|c|c|}
\hline Categorias & Subcategorias & Definição constitutiva segundo Tolbert e Zucker (1999) \\
\hline \multirow{3}{*}{ Estágio pré-institucional } & Forças Externas & $\begin{array}{l}\text { Forças causais exógenas à organização, geralmente derivadas de mudanças de } \\
\text { tecnologias, de legislações e das forças de mercado, as quais podem induzir à } \\
\text { introdução de inovações nas organizações e à criação de novos hábitos. }\end{array}$ \\
\hline & Inovação & Introdução de novas estruturas e criação de novos hábitos. \\
\hline & Habitualização & $\begin{array}{l}\text { Comportamentos padronizados organizados em arranjos estruturais concebidos } \\
\text { em resposta a problemas organizacionais específicos. }\end{array}$ \\
\hline \multirow{3}{*}{ Estágio semi-institucional } & $\begin{array}{l}\text { Monitoramento } \\
\text { interorganizacional }\end{array}$ & $\begin{array}{l}\text { Troca de conhecimentos entre as organizações, na busca de uma solução para } \\
\text { um determinado problema comum. }\end{array}$ \\
\hline & Teorização & $\begin{array}{l}\text { Definição de um problema organizacional a ser resolvido e a justificação do } \\
\text { arranjo estrutural formal com bases lógicas, por meio de teorias adequadas. }\end{array}$ \\
\hline & Objetificação & $\begin{array}{l}\text { Marca o desprendimento do significado da ação para o indivíduo e contribui } \\
\text { para a difusão da estrutura. }\end{array}$ \\
\hline \multirow{4}{*}{$\begin{array}{l}\text { Estágio da total } \\
\text { institucionalização }\end{array}$} & Impactos positivos & $\begin{array}{l}\text { Novas estruturas vêm ao encontro de resultados positivos. Caso esses resultados } \\
\text { não sejam alcançados pode haver desmotivação e descontinuidade na } \\
\text { implementação. }\end{array}$ \\
\hline & Resistência de grupo & $\begin{array}{l}\text { Atores afetados adversamente pelas estruturas e, assim, capazes de se } \\
\text { mobilizarem contra elas. }\end{array}$ \\
\hline & $\begin{array}{l}\text { Defesa de grupos de } \\
\text { interesse }\end{array}$ & Grupos que se propõem a atuar e a legislar a favor da nova estrutura. \\
\hline & Sedimentação & $\begin{array}{l}\text { Ocorre quando a institucionalização passa a fazer parte da história da } \\
\text { organização. }\end{array}$ \\
\hline
\end{tabular}

Fonte: elaborado pela autora a partir do objetivo e da literatura citada

As entrevistas ocorreram durante os meses de maio a setembro de 2018, totalizando aproximadamente quatro horas de gravação ao todo. No Quadro 2 constam os detalhes das entrevistas.

\begin{tabular}{|c|l|l|c|c|c|}
\hline Quadro 2 - Procedimentos da Pesquisa \\
\hline Entrevistado & Cargo & Escolaridade & $\begin{array}{l}\text { Tempo de } \\
\text { atuação }\end{array}$ & $\begin{array}{l}\text { Data da } \\
\text { entrevista }\end{array}$ & $\begin{array}{l}\text { Duração da } \\
\text { entrevista (min) }\end{array}$ \\
\hline EA1 & Sócio proprietário - Diretor & Superior & 20 anos & 21.05 .2018 & $38: 52$ \\
\hline EA2 & Gestora do Financeiro & Superior & 20 anos & 23.07 .2018 & $41: 24$ \\
\hline EA3 & Gestor Produção/Compras & Técnico & 20 anos & 25.07 .2018 & $56: 10$ \\
\hline EB1 & Sócio proprietário - Diretor & Superior & 15 anos & 11.06 .2018 & $30: 51$ \\
\hline EB2 & Coordenadora Qualidade & Superior & 2 anos & 25.09 .2018 & $23: 07$ \\
\hline EB3 & Diretora do Financeiro & Superior & 15 anos & 25.09 .2018 & $24: 46$ \\
\hline
\end{tabular}

Fonte: dados da pesquisa (2018)

Foram observadas diversas documentações que comprovam a implementação do SGQ na Empresa B e a tentativa na Empresa A. No Quadro 3 consta a documentação observada.

\section{Quadro 3 - Documentação observada}

\begin{tabular}{|l|l|}
\hline Empresa & Documentação observada \\
\hline Empresa A & $\begin{array}{l}\text { Lotes de produção; Ordens de Produção; Controle de Estoque/Compras; Instruções de Trabalho; } \\
\text { site (missão, visão, valores; respeito pelo meio ambiente); revistas especializadas. }\end{array}$ \\
\hline Empresa B & $\begin{array}{l}\text { Manual de Integração; Manual da Qualidade; Instruções de Trabalho; Indicadores; } \\
\text { Procedimentos; Ordens de Produção; Certificados; Premiações; site (missão, visão, valores; } \\
\text { atendimento a Portaria do INMETRO); quadros; fotos; revistas. }\end{array}$ \\
\hline
\end{tabular}

Fonte: dados da pesquisa (2018)

Além das entrevistas e da análise documental, foi utilizada a técnica da observação não participante nos ambientes das organizações. Os aspectos observados foram elencados com base nas categorias de análise e constam do Quadro 4. 
Institucionalização de novas práticas de controles de gestão: forças que potencializam ou comprometem o processo nos pequenos empreendimentos

\begin{tabular}{|l|l|}
\hline \multicolumn{2}{l|}{ Quadro 4 - Aspectos observados } \\
\hline Aspectos & Observação realizada \\
\hline Política de Gestão da Qualidade & $\begin{array}{l}\text { Contexto organizacional; Política de Qualidade; Missão; Visão; Valores; } \\
\text { Certificação. }\end{array}$ \\
\hline Práticas de Gestão da Qualidade & $\begin{array}{l}\text { Condições ambientais para o trabalho (iluminação, ruído, temperatura...); } \\
\text { Participação dos funcionários no processo (caixa de sugestões); } \\
\text { Relacionamento entre gestores e funcionários; Comunicação; Treinamentos }\end{array}$ \\
\hline
\end{tabular}

Fonte: dados da pesquisa (2018)

Para a análise dos dados foi utilizada a análise de conteúdo de Bardin. A análise de conteúdo é efetuada a partir de um agrupamento de técnicas de análise das comunicações, tais como entrevistas, documentos e observações (BARDIN, 2016). A análise dos dados foi realizada com o auxílio do software Atlas.ti 8.0® permitindo navegar e explorar todos os dados arquivados e codificados, facilitando a análise por meio de mapas chamados de networks ou redes.

\section{Apresentação e Análise dos Resultados}

As empresas estudadas operam no setor secundário, porém em segmentos diferenciados. A empresa A se enquadra no setor de metalurgia e está no mercado há 20 anos. A gestão é realizada entre os sócios e a empresa investe em pesquisa e desenvolvimento de novos produtos, atendendo diversos segmentos de negócios.

A empresa B atua no ramo de embalagens descartáveis há 15 anos e atende os estados da região sul e o Distrito Federal. Seu maior mercado está no Rio Grande do Sul. No ano de 2015 conquistou a Certificação ISO 9001:2008, fruto do interesse em oferecer produtos diferenciados, com o respaldo de uma certificação reconhecida internacionalmente.

\subsection{Processo de implementação do SGQ na Empresa A - Forças que comprometem a mudança}

O SGQ não está institucionalizado na Empresa A. As evidências encontradas foram dispostas em redes, resultantes da análise efetuada com o uso do software Atlas.ti 8.0®. Foram estabelecidas dez redes, distribuídas nos três estágios propostos, totalizando cento e onze citações.

\subsubsection{Estágio pré-institucional}

Neste estágio estão as forças externas que podem promover a inovação e a criação de novos hábitos, tais como pressões exercidas pelo mercado, legislação ou novas tecnologias. Com relação à subcategoria forças externas, havia um cliente estrangeiro que foi considerado uma força de mercado que fomentou mudanças na organização. Mesmo não exigindo a certificação ISO 9001, visitou a empresa para verificar se não havia nenhuma irregularidade. $\mathrm{O}$ fato de os entrevistados salientarem que o mercado está cobrando, alguns concorrentes são qualificados e os clientes exigem qualidade, reforça essa pressão externa.

Dessa forma, percebe-se que o cliente estrangeiro, enquanto força externa, motivou mudanças e a introdução de novas práticas de controle de gestão, com a alteração de comportamentos e o aumento da qualidade nos processos. Essas evidências relacionam-se à subcategoria inovação. Foi uma mudança de cultura, conforme evidenciado nas falas dos entrevistados. Houve uma tentativa de padronização das ações desenvolvidas, remetendo à subcategoria habitualização, proporcionando uma mudança de comportamento. Registros do caderno de campo apontam que diversos controles existentes na empresa partiram da tentativa de implantação da ISO 9001 e alguns passaram a fazer parte da rotina da empresa, permanecendo em uso até o presente estudo. 


\subsubsection{Estágio semi-institucional}

Ao serem indagados sobre a troca de experiências com outras organizações que estão implantando o SGQ, as evidências revelam que a busca por informações parte mais da direção, conforme relato do EA1: "No México eles estavam montando uma operação, então eu fui ver como era a operação para depois replicar aqui no Brasil [...] costumo ir a São Paulo, em Feiras de Varejo [...]" Participar de feiras e eventos ligados ao setor, visitar empresas e adotar as mesmas práticas, pode ser considerada uma evidência da subcategoria monitoramento organizacional. No entanto, estas trocas não estão totalmente ligadas à tentativa de implantação da ISO 9001, conforme as palavras do EA3: “[...] eu vi numa outra empresa e achei bem interessante. Daí eu copiei [...] Feiras sim. [...] Mas é uma falha que... a gente não faz.”

Em relação à subcategoria teorização, quanto a existência de normas, manuais, declarações formais de como e quando determinado procedimento deve ser adotado, as respostas dos entrevistados foram semelhantes. Existem alguns procedimentos formalizados em decorrência da legislação, tanto ambiental como trabalhista e outros pela tentativa de implantação ISO 9001, como relata o EA1 "o que nós temos formalizados são instruções de trabalho. Isso em função de que nós estávamos implantando a ISO". Da mesma forma o EA3 cita que "Então uma das primeiras coisas que o rapaz estava fazendo era um roteiro do trabalho, uma instrução de trabalho [...] Esses dias até eu estava lendo e se tu seguir aquilo ali, tu consegue entender todo o processo".

No que diz respeito à subcategoria objetificação, quanto ao significado atribuído aos novos controles decorrentes do SGQ, as respostas foram semelhantes sobre a divergência de significação. Enquanto para uns a nova prática era vista como necessária e capaz de conferir credibilidade junto ao mercado, para outros parecia não ser importante, sendo aceita apenas verbalmente, a exemplo da fala do EA1 "[...] eles entendem de certa forma, que é importante, mas na prática não acontece".

Para o EA2, parece que, embora a mudança tenha sido desafiadora no início, a partir do momento em que os resultados foram percebidos, houve uma motivação "[...] quando você vê que vem o resultado, as pessoas mesmo sentem orgulho do trabalho que estão fazendo".

Percebe-se, diante destas evidências, que a teorização teve início e foi bem estruturada até que houve uma discordância de significado e juntamente com a saída do consultor, a difusão acabou interrompida. Os registros do caderno de campo apontam uma expressão de frustação nos entrevistados quando mencionavam o fato de não terem prosseguido com o processo, quando estavam bem próximos da certificação.

\subsubsection{Estágio da total institucionalização}

A total institucionalização ocorre quando a nova estrutura passa a fazer parte da história da organização. Porém, segundo Tolbert e Zucker (1999), no decorrer desse estágio podem surgir forças capazes de comprometer a institucionalização a exemplo da falta de percepção dos resultados esperados e da resistência de alguns grupos, ou capazes de potencializar, a exemplo da defesa de grupos de interesse.

Neste sentido, questionados sobre a aceitação dos controles decorrentes da tentativa de implantação da ISO 9001, os entrevistados revelaram alguns fatores que podem ter contribuído para a descontinuidade na implementação, conforme as palavras do EA1: "Tem outras prioridades e isso fica como um segundo plano essa implementação e acaba não acontecendo na prática. [...] Ainda mais quando chegam os períodos de crise [...] Não enxergam a importância daquilo no curto prazo".

O EA2 ressalta que: "[...] não vou te dizer que abandonamos a ideia, mas [...] aquele trabalho específico foi deixado de lado”. Essas evidências dizem respeito à subcategoria impactos 
positivos, ou seja, quando os resultados esperados não são percebidos, ocorre a desmotivação e a descontinuidade do processo.

Da mesma forma, a resistência de indivíduos ou grupos pode ter contribuído para a interrupção do processo, conforme as palavras do EA1: "[...] não de forma deliberada, mas existe uma resistência até pela falta de conhecimento." Para o EA2 a resistência foi um fator significativo: "[...] quando surge o desafio do novo, bate o medo, bate a insegurança, não vou me adequar, vou ser demitido, não vou saber mexer no computador”. O EA3 salienta que: "[...] é aquela história: pra que eles querem isso? Ah, pra controlar [...] tudo que é controle é uma dificuldade para implantar. [...] a grande "massa" dos funcionários, eles têm resistência".

Quanto à subcategoria resistência de grupos, as evidências revelam que alguns grupos apresentaram resistências ao SGQ, talvez por não conhecerem os benefícios no longo prazo. Talvez por medo e insegurança pessoal acerca de novos controles. Talvez ainda pelas ações habituais, cuja mudança parecia desnecessária. Os registros do caderno de campo confirmam o sentimento de desapontamento dos entrevistados, tanto em relação a não obtenção da certificação quanto à resistência do pessoal interno. Dessa forma, pode-se deduzir que quando os indivíduos se sentem afetados pelas novas estruturas, podem ser capazes de se mobilizar contra elas.

Em relação à subcategoria defesa de grupos de interesse, os entrevistados revelaram que, embora em menor número, havia defensores desta nova prática. $\mathrm{O}$ "consultor de qualidade" foi identificado como uma das peças chave desse processo, conforme as palavras do EA2:

Nós contratamos uma pessoa [...] que foi bem importante [...] Ele trabalhou muito Qualidade. [...] o pessoal se colocou a disposição para ajudar [...] Faltou muito pouco [...] eu ainda tenho esperança que a gente vai voltar. Teve bastante gente... e tu vai semeando, vai enraizando nos outros. Então a gente trazia os dois opostos, a resistência e aqueles que abraçaram a ideia para mostrar que dá certo.

O EA3 salienta que a retomada do processo deve ocorrer, bem como cita alguns atores que defendem a nova estrutura: "Esse é um passo que tem que ser retomado o quando antes. [...] geralmente os chefes de setor apoiam”.

Pelas evidências apresentadas percebe-se que alguns grupos defenderam a ideia de implantação do SGQ. Especialmente os gestores. Além disso, o "consultor de qualidade" foi um elemento importante, responsável por incentivar o uso de diversos controles. As anotações do caderno de campo reforçam a ideia de que o processo deve ser retomado. Isso fica claro nas expressões faciais e nos gestos dos entrevistados, ao mencionarem a importância destes controles na qualidade de suas ações.

Quanto à subcategoria sedimentação, alguns controles permanecem em uso. Evidências são percebidas nas palavras dos entrevistados, a exemplo do EA1: "[...] instruções de trabalho. Isso em função de que nós estávamos implantando a ISO. Foi uma das coisas que ajudou e que ficou. [...] na época nós estávamos fazendo, ficou e ajuda bastante”.

Da mesma forma o EA2 salienta que: "[...] coisa que não fazíamos e que agora a gente faz que é a pesquisa de satisfação. [...] isso também foi uma implantação nova que não tinha e deu bastante resultado. [...] Existe uma instrução de trabalho [...] ela abre o computador dela e ali vai ter o passo a passo, como ela faz". As palavras do EA3 seguem a mesma direção: "O relatório de compras é um. [...] muita coisa do que foi implantado se segue." Essas evidências foram confirmadas quando da observação e análise documental.

Ao término dessa seção, percebe-se que o SGQ não está institucionalizado na empresa A, apesar de alguns controles permanecerem em uso. Pode-se deduzir que, embora algumas forças tenham potencializado o processo de institucionalização desta prática de controle de gestão, outras forças internas, a exemplo da resistência, podem ter dificultado a ponto de comprometer a implementação em sua plenitude. Além disso, percebe-se que esta resistência esteve presente desde o início do processo, e não apenas em estágios específicos como proposto no modelo de Tolbert e Zucker. 


\subsection{Posicionamento do processo de implementação do SGQ na Empresa B - Forças que potencializam a mudança}

As evidências foram dispostas em redes, resultantes da análise efetuada com o uso do software Atlas.ti 8.0®, a exemplo da Empresa A, e totalizaram setenta e cinco citações.

\subsubsection{Estágio pré-institucional}

Em relação à subcategoria forças externas, os entrevistados evidenciam que não houve uma exigência externa, mas sim o interesse da própria empresa na implantação do SGQ. Conforme comenta o EB2: "Na verdade acredito que foi a questão mesmo do mercado. Tu demonstrar para o teu cliente que tu é qualificado, mais do que o teu concorrente. E exigência mesmo, do INMETRO”. Nas palavras do EB3 fica clara a preocupação com o mercado: “[...] com a ISSO a gente começou a ter todos os procedimentos [...] queríamos competir mas tinha que ter um diferencial. [...] Não teve nenhuma exigência externa, foi mais da vontade nossa de se diferenciar".

Pelas evidências apresentadas, percebe-se que o mercado, mesmo não exigindo formalmente a certificação ISSO 9001, pode ser considerado uma força externa que motivou mudanças na empresa. A preocupação em oferecer produtos com qualidade e estar mais qualificado que a concorrência, pode ser um indicativo de pressão externa. Em relação à legislação, seus produtos são forçados a seguir determinações do INMETRO, o que pode ter contribuído para a implantação do SGQ. Essa evidência fica clara não apenas nas palavras dos entrevistados, mas no site da empresa, que destaca o atendimento a esta exigência.

Quanto à subcategoria inovação, as evidências apontam a inovação nos controles de gestão e a criação de novos hábitos. Além de estarem presentes nas falas dos entrevistados, os documentos analisados comprovam a inclusão de novas estruturas. As palavras do EB1 reforçam essas evidências: "Teve inúmeros controles que nós não tínhamos especificamente e fomos adotando, fomos monitorando, implantando [...] os indicadores. Todos são relevantes".

Em relação à subcategoria habitualização, diante destas evidências, percebe-se que a implantação do SGQ proporcionou a padronização das ações, criando novos hábitos, a exemplo do monitoramento dos indicadores e da análise do ambiente interno e externo. As anotações do caderno de campo evidenciam o entusiasmo dos entrevistados ao citarem a evolução da empresa e dos seus controles de gestão, bem como o sentimento de orgulho por perceberem o resultado do esforço despendido.

\subsubsection{Estágio semi-institucional}

Em relação à subcategoria monitoramento interorganizacional, as respostas evidenciam que foram realizados cursos na área de qualidade e houve consultorias especializadas. Estas iniciativas proporcionaram a troca de conhecimento, como destacado no relato do EB2: “[...] conheci a gestora financeira de uns cursos que fizemos na área da Qualidade [...] Alguns parceiros sim. Há essa troca de informações [...] O diretor está sempre participando de eventos no ramo". Da mesma forma o EB3 comenta que: "Foram dois anos de estudo. Para conhecer toda a norma. Foi um ano de aulas na Associação e o outro ano o consultor vinha na empresa para a gente montar todo o trabalho. [...] Nós fomos o ano passado para São Paulo”.

Quanto à subcategoria teorização, as respostas dos entrevistados evidenciam a presença de formalização, a exemplo das palavras do EB1: "Tem o manual da qualidade. Tem os procedimentos da produção. [...] Estão formalizados". O EB2 confirma: "Tem. Toda a documentação. Todo o manual da qualidade, a política da qualidade, os procedimentos, instruções, manual de ingresso na empresa”. 
Diante dessas evidências, da análise documental e da observação, percebe-se que a empresa possui os procedimentos formalizados. Do Manual de Integração entregue ao funcionário no momento de sua admissão, até o Manual da Qualidade com as políticas, procedimentos e instruções a serem seguidos por todos os atores da organização, confirmam esta padronização. As anotações do caderno de campo revelam o sentimento de orgulho dos entrevistados ao falarem destas conquistas, bem como o cuidado com os documentos impressos e a organização nas pastas eletrônicas.

No que diz respeito à subcategoria objetificação, os entrevistados ressaltaram a dificuldade inicial junto aos funcionários operacionais. Enquanto para os gestores a nova prática era vista como um sonho realizado, de garantir a qualidade para o cliente e consequentemente a legitimidade perante o campo mais amplo, para outros parecia apenas burocracia, preenchimento de papel e mais trabalho.

Apesar da divergência inicial de significado, gradativamente os envolvidos foram percebendo sua importância e colaborando com a difusão da nova estrutura. Alguns fragmentos das entrevistas confirmam essa evidência, a exemplo das palavras do EB1: "No início acharam que seria mais burocrático e iria só encher papel [...] Se tornou uma rotina, embora com ajustes para fazer, já está dentro do contexto. [...] Viram que é um caminho sem volta. Que é uma necessidade e que é importante".

Pelas evidências apresentadas, percebe-se que as estruturas foram amplamente disseminadas. $\mathrm{O}$ fato de os gestores terem participado de curso sobre Gestão da Qualidade pode ter contribuído para a difusão dessas novas práticas. Os registros do caderno de campo ressaltam a expressão de orgulho dos gestores ao falarem sobre a conquista da certificação, independente dos obstáculos iniciais. O grau de consenso social dos gestores e o valor atribuído a esta nova prática, podem ter sido decisivos para que sua difusão fosse amplamente disseminada.

\subsubsection{Estágio da total institucionalização}

Quanto à subcategoria impactos positivos, os entrevistados revelaram que o processo foi implementado gradativamente. $\mathrm{O}$ objetivo foi conscientizar os indivíduos quanto a importância desses novos controles e os resultados decorrentes de seu uso, conforme as palavras do EB2: "Todos os setores hoje, os maiores, já estão padronizados [...] A gente tenta fazer de forma que atenda a norma, mas que facilite o trabalho e que traga algum resultado, porque senão não adianta nada”.

Verificou-se que os resultados esperados foram sendo percebidos progressivamente, principalmente pelos atores do operacional, colaborando para a institucionalização do SGQ. Analisar indicadores, fazer projeções, controlar perdas e elaborar um plano de ação para corrigir o que não condiz com a meta, são indicativos dos resultados obtidos com esses controles.

Sobre a subcategoria resistência de grupos, os entrevistados revelaram que inicialmente houve a resistência do operacional. Uns por dificuldades com a mudança de hábitos. Outros por medo do novo e alguns por entenderem que haveria mais trabalho, a exemplo das palavras do EB1: "[...] de certo modo você tem a resistência à mudança. Primeira resistência é: "sempre foi assim" lá na produção e aqui no escritório. [...] Mas especificamente acho que era receio ao novo, à novidade". No depoimento do EB2 "O pessoal acha que a ISO é burocracia. Engessa, dificulta [...] Assim como tem pessoas [...] que são mais resistentes pelo medo do fazer [...] tem as mais jovens que é a questão do: "vai me dar mais trabalho fazer isso." [...] Vou ter que fazer mais do que já estou fazendo.

Quanto à subcategoria defesa de grupos de interesse, os entrevistados apontaram a existência de grupos de defensores com força suficiente para mobilizar e legislar em prol da nova estrutura, em especial os ligados à gestão, conforme relatos do EB3: "A responsável na fábrica vestiu a camisa e o rapaz que ajuda na produção também”. Observou-se que, além dos gestores, 
alguns atores ligados ao operacional perceberam a importância dos controles e passaram a defender implantação do SGQ.

Em relação à subcategoria sedimentação, as respostas dos entrevistados evidenciam a institucionalização do SGQ, a exemplo do EB1: “[...] nos certificamos no INMETRO, conseguimos a ISO 9001 [...]Se tornou uma rotina, embora com ajustes para fazer, já está dentro do contexto". Da mesma forma o EB2 comenta: "[...] vai ter auditoria de recertificação, já na versão $2015 "$ ".

Diante das evidências apresentadas, percebe-se que os controles existentes na Empresa B decorrem da implantação do SGQ. Esses controles passaram a fazer parte da rotina da organização, da sua história, uma vez que desde 2015 mantém a certificação ISO 9001. Os registros do caderno de campo evidenciam a satisfação e o orgulho com que os entrevistados falaram nesta conquista e nos resultados alcançados. Principalmente por serem a única empresa da cidade que iniciou o processo e conseguiu concretizá-lo.

Ao término dessa seção, percebe-se que o SGQ está institucionalizado na empresa B, fazendo parte de sua história. Perante as evidências apresentadas, pode-se inferir que forças externas e internas potencializaram o processo de institucionalização desta prática de controle de gestão. Apesar da resistência inicial de grupos específicos, o trabalho efetivo dos gestores no sentido de realizar reuniões de conscientização, permitiu que essas forças internas não fossem obstáculo para a institucionalização da nova estrutura.

\subsection{Discussão das forças que potencializam a implementação do SGQ}

As pressões decorrentes do mercado e a busca por legitimidade perante a sociedade, forçam as empresas a adotarem práticas que são socialmente valiosas dentro de um campo institucional (BERRONE et al., 2013). Dessa forma, certificações e acreditações podem ser adotadas como critério de legitimidade (SCOTT, 2001). Em relação a estudos anteriores, há semelhanças nas evidências de competição, pressões sociais e busca por legitimidade, bem como de atores-chaves no interior da organização.

A pesquisa de Oyadomari et al. (2008b) concluiu que a mudança decorre de pressões do ambiente e busca por legitimação. Destacam ainda que o papel das consultorias é importante na adoção de novas práticas. Embora feita com empresas de médio e grande porte, os resultados são semelhantes aos obtidos nas pequenas empresas do presente estudo. As pressões decorrentes do cliente estrangeiro na empresa A e do mercado na empresa B motivaram a mudança nos controles gerenciais, especialmente a busca de legitimidade perante a sociedade. O profissional contratado especificamente para auxiliar na implantação do SGQ na empresa A e a formação específica dos gestores na empresa $\mathrm{B}$, foram relevantes ao processo.

Na pesquisa de Lavarda, Barrachina e Ripoll (2010), os resultados revelaram que os motivos estavam associados a fatores externos e internos, relacionados ao desempenho empresarial e à competitividade. Não foram encontradas evidências relacionadas a necessidade de legitimação. A pesquisa destes autores difere dos achados no presente estudo em relação à legitimidade, uma vez que as empresas consideram a certificação ISO 9001 como forma de obter reconhecimento no mercado. Porém, assemelha-se na questão da competitividade e desempenho empresarial, uma vez que as empresas pretendiam tornarem-se mais competitivas e alavancar seu desempenho.

Vicente, Major e Pinto (2011) avaliaram o grau de mudança nas práticas de controles de gestão em empresas de Portugal e identificaram os fatores que influenciaram essa mudança. As pressões decorrentes do mercado externo foi o maior impulsionador da mudança nos controles de gestão, seguido das influências da gestão interna. Estes resultados assemelham-se aos achados do presente estudo, confirmando que o mercado acaba por forçar as empresas a acompanhar suas tendências, a exemplo da certificação ISSO 9001, bem como a influência da direção e gestores específicos na implantação do SGQ. 
Angonese e Lavarda (2017) analisaram os fatores motivadores do processo de mudança do sistema de contabilidade gerencial, em uma sociedade anônima. Dos seis fatores analisados, apenas pressão social do ambiente e improvisação se fizeram presentes de forma concomitante, exercendo influência no processo de mudança, mas com intensidades diferentes. Os resultados da pesquisa assemelham-se parcialmente aos achados do presente estudo, uma vez que as empresas A e B sofreram pressão social do ambiente, porém a direção, com seu poder hierárquico, decidiu pela implantação do processo.

Gamage e Gooneratne (2017) exploraram como os controles de gestão se formam em uma organização, em meio às tensões entre as forças institucionais externas e as dinâmicas internas decorrentes dos diferentes poderes e interesses dos gerentes, bem como das normas intraorganizacionais, regras e pressupostos assumidos. Os achados revelam que os controles gerenciais tomaram forma em meio a pressões externas, especificamente de clientes, e dinâmicas internas como interesses de atores-chave, que respondem estrategicamente a pressões externas. Os resultados daquela pesquisa assemelham-se aos achados do presente estudo, uma vez que as empresas estudadas promoveram mudanças em seus controles de gestão principalmente em função do mercado. Mudanças estas promovidas pela ação deliberada da direção e gestores específicos.

Observa-se nas pesquisas citadas, que o atendimento a pressões sociais na busca por legitimidade e os atores-chave, constituem fatores que podem potencializar o processo de institucionalização de novas práticas de controle gerencial. Dessa forma, cada organização pode responder de maneira diversa diante do mesmo campo institucionalmente complexo (SVENNINGSEN; BOXENBAUM; RAVASI, 2016). Neste sentido, percebe-se que as forças que potencializaram a mudança foram semelhantes em ambas as empresas. Porém, na empresa A não foram suficientes para garantir o sucesso na institucionalização.

\subsection{Discussão das forças que comprometem a implementação do SGQ}

Pressões que resultam de modos de pensar, poder e confiança podem ser exemplos de fatores de resistência presentes no processo de mudança (SCAPENS, 2006; BUSCO; QUATTRONE; RICCABONI, 2007) e no ambiente socioinstitucional em que as organizações estão inseridas (ANGONESE; LAVARDA, 2014). Neste sentido, a resistência envolve diversos fatores e está presente no processo de mudança da contabilidade gerencial, constituindo um elemento interno das organizações (BURNS; SCAPENS, 2000), pois reside na natureza do ser humano (ANGONESE; LAVARDA, 2014). Dessa forma, indivíduos ou grupos podem resistir ou prejudicar o processo de mudança (BURNS; SCAPENS, 2000). Em relação a estudos anteriores, há semelhanças nos fatores de resistência, baixa teorização e impossibilidade de visualização de resultados positivos.

Vicente, Major e Pinto (2011) investigaram o grau de mudança ocorrido no controle gerencial em empresas de Portugal. Os resultados revelaram dois fatores inibidores da mudança: adaptação a novas tecnologias e cultura empresarial conservadora. Os achados assemelham-se aos resultados do presente estudo. O medo e insegurança pessoal acerca de novos controles, bem como a dificuldade de mudança em relação a ações habituais e a realização de práticas em desconformidade com as regras, podem ter comprometido a mudança nas práticas de gestão na Empresa A.

Angonese e Lavarda (2014) analisaram os fatores de resistência presentes no processo de implementação de um sistema integrado de gestão. Os achados mostraram que o processo de mudança enfrenta um conjunto particular de pressões por resistências internas nas organizações, cada qual com sua intensidade, tais como insegurança ontológica, confiança, inércia, falta de conhecimento, aceitação de rotinas e decoupling. Segundo os autores, esses fatores são despertados no início do processo de mudança e, caso reúnam força suficiente, podem interrompêlo. Os achados destes autores, assemelham-se aos resultados do presente estudo em relação a 
Empresa A. Resistência interna por falta de percepção de resultados positivos, medo e insegurança pessoal acerca de novos controles, ações habituais cuja mudança parecia desnecessária e ações realizadas em desconformidade com as regras. Estes fatores, existentes desde o início do processo, podem ter interferindo na sua continuidade.

Wanderley e Soeiro (2016) investigaram um caso de insucesso na implantação do Balanced Scorecard (BSC) em uma empresa de energia elétrica. O BSC foi implementado por motivos técnicos e depois por legitimação. Foi inicialmente apoiado pela equipe de gestão, porém, após alguns meses, não era uma prioridade na organização e como consequência perdeu apoio. Os resultados daquela pesquisa assemelham-se aos achados deste estudo em relação a Empresa A. Motivados por um cliente estrangeiro, a direção optou em implantar o SGQ, em busca de legitimidade. O processo foi iniciado, porém, após um período de quase dois anos e alguns controles implantados, perdeu espaço para outras prioridades.

Dessa forma, é necessário compreender que as forças não provêm apenas de fontes externas ao agente, mas "por meio da interpretação, do significado que ele atribui ao contexto no qual imerge e emerge a prática social" (MACHADO-DA-SILVA; FONSECA; CRUBELLATE, 2005 p.18). Assim os atores organizacionais passam a ser os portadores dos significados institucionais (ZILBER, 2002), ao estimularem ações por meio da interpretação de fatores externos e internos que podem ser legitimados por meio do compartilhamento e socialização (MACHADO-DASILVA; FONSECA; CRUBELLATE, 2005).

Neste sentido, a empresa B pode ter obtido sucesso na implementação a partir do envolvimento de todos os atores organizacionais. Reuniões de conscientização sobre a importância da nova estrutura e os resultados visualizados por meio dos indicadores, podem ter sido fundamentais para que a interpretação do significado do SGQ fosse compartilhada pela maioria dos indivíduos, potencializando assim sua institucionalização. Em relação à Empresa A, apesar da contratação de um consultor, parece que a divergência de significados em relação a nova prática gerou conflitos de interesse, permitindo que novas prioridades fossem estabelecidas e o processo interrompido.

Por fim, percebe-se que o significado atribuído pelos diferentes atores organizacionais, em ambas as empresas estudadas, foi imprescindível para que a nova estrutura fosse institucionalizada na Empresa B e fosse interrompida na Empresa A.

\section{Considerações Finais}

Esta pesquisa analisou as forças que potencializam ou comprometem o processo de institucionalização de novas práticas de controle de gestão, em pequenas empresas. Para tal, foi utilizada a teoria institucional, na vertente da NSI, por meio do modelo de Tolbert e Zucker (1999).

Como fatores externos que potencializaram a implantação do SGQ, ficou evidente a pressão de instituições extraorganizacionais (sociais, econômicas e políticas) em ambas as empresas estudadas. Em especial a competição de mercado, pressões sociais (legislação ambiental e trabalhista), busca por legitimidade e credibilidade.

Em relação aos fatores internos, a forma de pensar compartilhada por indivíduos específicos, foi fundamental para a implementação do SGQ na Empresa B. Porém, insuficientes na Empresa A, que passou a eleger novas prioridades. Seguindo a dialética proposta por Seo e Creed (2002), evidenciou-se que as estruturas organizacionais são produtos de forças internas e externas ao ambiente em que atuam.

Em relação aos fatores que comprometem o processo de mudança, percebe-se que a resistência ocorre espontaneamente no início do processo. Porém, nem sempre impede a implementação da nova prática. Das empresas estudadas, uma conseguiu superar a resistência inicial e obteve sucesso na implementação, enquanto a outra precisou interromper o processo, 
comprovando estudos anteriores que argumentam que cada organização pode responder de maneira diferente perante o mesmo campo institucionalmente complexo.

Estas evidências confirmam estudos anteriores afirmando que a mudança ocorre por meio de uma mescla de fatores externos e internos, que enfrentam resistência de ordem interna. Tanto os fatores motivadores como os de resistência possuem sua intensidade, variando conforme o contexto organizacional.

Portanto, de acordo com Tolbert e Zucker (1999), constata-se que o processo de institucionalização do SGQ encontra-se no estágio de total institucionalização na empresa B. O significado das novas práticas passou a ser percebido pelos diferentes atores. A resistência inicial foi sanada e desde 2015 esta estrutura faz parte da história da organização. Porém, o SGQ não está institucionalizado na empresa A, embora alguns controles decorrentes da implementação permaneçam em uso. Entende-se que, pelo modelo estudado, o processo de institucionalização avançou além do primeiro estágio, sendo interrompido na fase da objetificação. A divergência de significados entre os atores organizacionais pode ter sido um fator decisivo para a interrupção do processo, pois novas prioridades foram consideradas.

Diante do exposto, percebe-se que forças presentes no processo de institucionalização, com origem em diferentes instituições (internas e externas), podem potencializar ou comprometer a mudança desde o início do processo, possibilitando a contribuição teórica em relação ao entendimento de como e porque ocorre a mudança nos controles de gestão, especialmente nos pequenos empreendimentos. Como contribuição empírica, a partir da compreensão dos fatores externos e internos que potencializam o processo de inovação, as organizações podem planejar suas ações, otimizar o uso dos recursos e contribuir para mudanças bem sucedidas. Da mesma forma, ao identificar as forças que podem comprometer o processo, o estudo contribui para entender o papel da resistência e do significado atribuído à nova prática.

Recomendam-se novas pesquisas, em diferentes contextos e situações, a fim de verificar se há semelhança nos resultados. Por se tratar de um estudo qualitativo, sugerem-se pesquisas que envolvam outras técnicas de coleta e análise dos dados, como grupo focal e análise do discurso, a fim de contribuir com novos achados.

\section{Referências}

ANGONESE, Rodrigo; LAVARDA, Carlos Eduardo Facin. Análise dos Fatores de Resistência Envolvidos no Processo de Mudança no Sistema de Contabilidade Gerencial. Revista

Contabilidade \& Finanças - USP, São Paulo, v. 25, n. 66, p. 214-227, set./out./nov./dez. 2014. https://doi.org/10.1590/1808-057x201410810

ANGONESE, Rodrigo; LAVARDA, Carlos Eduardo Facin. Fatores para a implementação da mudança em sistemas de contabilidade gerencial. Enfoque: Reflexão Contábil. UEM, Paraná, v. 36, n. 1, p. 139-154, jan./abr. 2017. https://doi.org/10.4025/enfoque.v36i1.30479

ASSOCIAÇÃO BRASILEIRA DE NORMAS TÉCNICAS - Boletim ABNT, v. 12, n. 148, nov./dez. 2015. Disponível em:

<http://abnt.org.br/images/boletim/Boletim_ABNT_148_nov_dez_2015_NET.pdf>.Acesso em: 04 jun. 2018.

BARDIN, Laurence. Análise de conteúdo. São Paulo: Edições 70, 2016.

BERGER, Peter L.; LUCKMANN, Thomas. A construção social da realidade: tratado de sociologia do conhecimento. 3. ed. Petropolis: Vozes, 1976. 
BERRONE, Pascual et al. Necessity as the mother of 'green' inventions: institutional pressures and environmental innovations. Strategic Management Journal, New Jersey, v. 34, n. 8, p. 891-909, Aug. 2013. https://doi.org/10.2307/23471046

BURNS, John; EZZAMEL, Mahmoud; SCAPENS, Robert. The challenge of management accounting change. Behavioural and cultural aspects of change management. CIMA. Elsevier, 2003.

BURNS, John; SCAPENS, Robert W. Conceptualizing management accounting change: an institutional framework. Management Accounting Research, v. 11, n. 1, p. 3-25, 2000. http://dx.doi.org/10.1006/mare.1999.0119

BUSCO, Cristiano; QUATTRONE, Paolo; RICCABONI, Angelo. Management accounting: issues in interpreting its nature and change. Management Accounting Research, v. 18, p. 125149, 2007. https://doi.org/10.1016/j.mar.2007.04.003

COVALESKI, Mark A. et al. Budgeting research: three theoretical perspectives and criteria for selective integration. In: CHAPMAN, Christopher S.; HOPWOOD, Anthony G.;

SHIELDS, Michael D. (Orgs.). Handbook of Management Accounting Research. Oxford, UK: Elsevier, 2007.

COVALESKI, Mark A.; DIRSMITH, Mark W.; SAMUEL, Sajay. Management accounting research: The contributions of organizational and sociological theories. Journal of Management Accounting Research, v. 8, p. 1-35, 1996.

DIMAGGIO, Paul J.; POWELL, Walter W. The iron cage revisited: institutional isomorphism and collective rationality in organizational fields. American Sociological Review, v. 48, n. 2, p. 147-160, Apr. 1983. https://doi.org/10.2307/2095101

EISENHARDT, Kathleen M. Building Theories from Case Study research. Academy of Management Review, v. 14, n. 4, p. 532-550, 1989. https://doi.org/10.2307/258557

FLICK, Uwe. Introdução à pesquisa qualitativa. Porto Alegre: ArtMed, 2009.

FREZATTI, Fabio et al. A pesquisa em contabilidade gerencial no Brasil: Desenvolvimento, dificuldades e oportunidades. Revista Universo Contábil, FURB, Blumenau, v. 11, n. 1, p. 4768, jan./mar. 2015. https://doi.org/10.4270/ruc.2015103

FREZATTI, Fabio et al. Análise crítica da contabilidade gerencial no Brasil sob a ótica dos professores de pós-graduação stricto sensu da área. BBR - Brazilian Business Review, v. 6, n. 3, p. 282-298, set./dez. 2009. http://dx.doi.org/10.15728/bbr.2009.6.3.4

FREZATTI, Fabio; JUNQUEIRA, Emanuel; BIDO, Diógenes de Souza; NASCIMENTO, Arthur R.; RELVAS, Tânia R. S.. Antecedentes da definição do design do sistema de controle gerencial: evidências empíricas nas empresas brasileiras. Brazilian Business Review. v.9, n.1, p. 134-155, jan./abr. 2012. http://dx.doi.org/10.15728/bbr.2012.9.1.6

FREZATTI, Fabio. Agrupamentos dos Perfis da Contabilidade Gerencial no Brasil. Revista Contabilidade, Gestão e Governança (CGG), v. 8, n. 1, p. 9-39, jan./jun. 2005. 
GAMAGE, Sujeewa D. D.; GOONERATNE, Tharusha. Management controls in an apparel group: an institutional theory perspective. Journal of Applied Accounting Research, v 18, p.223-241, 2017. http://dx.doi.org/10.1108/JAAR-09-2015-0075

GUARIDO FILHO, Edson Ronaldo; MACHADO-DA-SILVA, Clóvis L.; GONÇALVES, Sandro A. Institucionalização da Teoria Institucional no contexto dos estudos organizacionais no Brasil. In: ENCONTRO NACIONAL DOS PROGRAMAS DE PÓS-GRADUAÇÃO EM ADMINISTRAÇÃO - EnANPAD, 33, São Paulo, 2009. Anais eletrônicos [...]. São Paulo: ANPAD, set. 2009. Recuperado de http://www.anpad.org.br/diversos/down_zips/45/EOR2085.pdf

GUERREIRO, Reinaldo et al. O entendimento da contabilidade gerencial sob a ótica da teoria institucional. Organizações \& Sociedade, v. 12, n. 35, p. 91-105, out./dez. 2005. https://doi.org/10.1590/S1984-92302005000400005_

GUERREIRO, Reinaldo; CORNACHIONE JR, Edgar Bruno; SOUTES, Dione Olesczuk. Empresas que se destacam pela qualidade das informações a seus usuários externos também se destacam pela utilização de artefatos modernos de contabilidade gerencial. Revista Contabilidade \& Finanças, v. 22, n. 55, p. 88-113, 2011. https://doi.org/10.1590/S1519-70772011000100006_

GUERREIRO, Reinaldo; FREZATTI, Fabio; CASADO, Tânia. Em Busca de um Melhor Entendimento da Contabilidade Gerencial - Conceitos da Psicologia, Cultura Organizacional e Teoria Institucional. Revista Contabilidade \& Finanças. São Paulo: Edição Comemorativa, p. 7-21, set. 2006. https://doi.org/10.1590/S1519-70772006000400002

GUERREIRO, Reinaldo; PEREIRA, C. A.; FREZATTI, F. Aplicação do modelo de Burns e Scapens para avaliação do processo de institucionalização da contabilidade gerencial. Organizações \& Sociedade, v. 15, n. 44, p. 45-62, 2008. https://doi.org/10.1590/S198492302008000100003

HOPPER, Trevor; BUI, Binh. Has Management Accounting Research been critical? Management Accounting Research, v. 31, p. 10-30, 2016. http://dx.doi.org/10.1016/j.mar.2015.08.001

INSTITUTO BRASILEIRO DE GEOGRAFIA E ESTATÍSTICA - IBGE. Estatísticas do cadastro central de empresas: 2015. Coordenação de Metodologia das Estatísticas de Empresas, Cadastros e Classificações. Rio de Janeiro: IBGE, 2017. Disponível em: https://biblioteca.ibge.gov.br/visualizacao/livros/liv100618.pdf. Acesso em: 04 mar. 2018.

KOS, Sonia Raifur et al. Compreensão e utilização da informação contábil pelos micro e pequenos empreendedores em seu processo de gestão. Enfoque: Reflexão Contábil. v. 33, n. 3, p. 35-50, set./dez. 2014. https://doi.org/10.4025/enfoque.v33i3.21069

LAVARDA, Carlos Eduardo Facin; BARRACHINA PALANCA, Mercedes; RIPOLL FELIU, Vicente. Motivos de Cambio de los Sistemas Contables de Gestión en las Pequeñas Empresas. Contabilidade Vista \& Revista, Universidade Federal de Minas Gerais, v. 21, n. 4, p. 89-122, out./dez. 2010. 
LIGUORI, Mariannunziata; STECCOLINI, Ileana. Accounting change: explaining the outcomes, interpreting the process. Accounting, Auditing and Accountability Journal, v. 25, n. 1, p. 27-70, 2012. https://doi.org/10.1108/09513571211191743

LUZ, Igor Pereira da; LISBOA, Felipe V.; LAVARDA, Carlos E. F.; VICENTE, Ernesto F. R. Teoria Institucional: uma análise bibliométrica na pesquisa em Contabilidade. Revista de Educação e Pesquisa em Contabilidade (REPeC), v. 12, n. 4, 2018. https://doi.org/10.17524/repec.v12i4.1873

MACHADO-DA-SILVA, Clóvis L.; FONSECA, Valéria Silva da; CRUBELLATE, João Marcelo. Estrutura, Agência e Interpretação: Elementos para uma abordagem recursiva do processo de institucionalização. Revista de Administração Contemporânea. [online]. Edição Especial, v. 1, p. 09-39, 2005. https://doi.org/10.1590/S1415-65552005000500002.

MACHADO-DA-SILVA, Clóvis L.; GONÇALVES, Sandro Aparecido. Nota técnica: a teoria institucional. In: CLEGG, S. R. et al. Handbook de estudos organizacionais: modelos e novas questões em estudos organizacionais. São Paulo: Atlas, v. 1, p. 220-226, 1999.

MEYER, John. W.; ROWAN, Brian. Institutionalized organizations: formal structure as myth and ceremony. American Journal of Sociology, v. 83, n. 2, p. 340-363, 1977.

https://doi.org/10.1086/226550

MOLL, J.; BURNS, John; MAJOR, Maria. Institutional Theory. In Z. Hoque. (Ed.).

Methodological issues in accounting research: theories, methods and issues. London: Siramus. 2006.

NASCIMENTO, Artur Roberto do; JUNQUEIRA, Emanuel; MARTINS, Gilberto de Andrade. Pesquisa acadêmica em contabilidade gerencial no Brasil: análise e reflexões sobre teorias, metodologias e paradigmas. Revista de Administração Contemporânea, v. 14, n. 6, p. 1113 1133, 2010. https://doi.org/10.1590/S1415-65552010000700008.

OYADOMARI, José Carlos Tiomatsu et al. Análise dos fatores que favorecem a institucionalização da Value Based Management (VBM) à luz dos argumentos de teóricos da vertente new institutional sociology (NIS). Revista Universo Contábil, FURB, Blumenau, v. 4, n. 2, p. 06-21, abr./jun. 2008a. http://dx.doi.org/10.4270/ruc.20084

OYADOMARI, José Carlos Tiomatsu; MENDONÇA NETO, Octávio R. de; CARDOSO, Ricardo Lopes; LIMA, Marianda P. de. Fatores que influenciam a adoção de artefatos de controle gerencial nas empresas brasileiras. Um estudo exploratório sob a ótica da teoria institucional. RCO - Revista de Contabilidade e Organizações, FEA-RP/USP, v. 2, n. 2, p. 55-70, jan./abr. 2008b. https://doi.org/10.11606/rco.v2i2.34705

PAULO, Alessandro Souza de; CINTRA, Yara Consuelo. O uso de artefatos de contabilidade gerencial no ciclo de vida de empresas do setor têxtil: O caso ACR Fashion. Revista de Contabilidade do Mestrado em Ciências Contábeis da UERJ (online), Rio de Janeiro, v. 23, n.1, p. 88-106, jan./abr. 2018. https://doi.org/10.12979/rcmccuerj.v23i1.39297

PEREIRA, Carlos Alberto; GUERREIRO, Reinaldo. Avaliação do processo de mudança da contabilidade gerencial sob o enfoque da teoria institucional: o caso do Banco do Brasil. In: ENCONTRO NACIONAL DOS PROGRAMAS DE PÓS-GRADUAÇÃO EM 
ADMINISTRAÇÃO - EnANPAD, 29, Brasília, 2005. Anais eletrônicos [...] Brasília: ANPAD, 2005.

RIBEIRO, João A.; SCAPENS, Robert W. Institutional theories in management accounting change: contributions, issues and paths for development. Qualitative Research in Accounting \& Management, v. 3, n. 2, p. 94-111, 2006. https://doi.org/10.1108/11766090610670640

RUSSO, Paschoal Tadeu; PARISI, Cláudio; PEREIRA, Carlos Alberto. Evidências das forças causais críticas dos processos de institucionalização e desinstitucionalização em artefatos da contabilidade gerencial. RCC - Revista Contemporânea de Contabilidade. UFSC, Florianópolis, v. 13, n. 30, p. 03-33, set./dez. 2016. http://dx.doi.org/10.5007/21758069.2016v13n30p3

SANTOS, Vanderlei dos; DOROW, Diego Roberto; BEUREN, Ilse Maria. Práticas gerenciais de micro e pequenas empresas. Revista Ambiente Contábil. Universidade Federal do Rio Grande do Norte, v. 8, n. 1, p. 153-186, jan./jun. 2016.

SCAPENS, Robert W. Never mind the gap: towards an institutional perspective on management accounting practice. Management Accounting Research, v. 5, n. 3/4, p. 301-321, 1994. https://doi.org/10.1006/mare.1994.1019

SCAPENS, Robert W. Understanding management accounting practices: a personal journey. The British Accounting Review, v. 38, n. 1, p. 1-30, 2006.

https://doi.org/10.1016/j.bar.2005.10.002

SCOTT, W. Richard. Institutions and organizations. 2. ed. Thousand Oaks: Sage, 2001.

SCOTT, W. Richard. Institutional Theory: contributing to a theoretical research program. In: SMITH, K. G.; HITT, M. A. (Org.). Great minds in management: the process of theory development. Oxford: Oxford University Press, p. 460-484, 2005.

SCOTT, W. R. Symbols and organizations: from Barnard to the institutionalists. In: WILLIAMSON, O. (Org.). Organization theory: from Chester Barnard to the present and beyond. New York: Oxford University Press, p. 38-55, 1995.

SEO, Myeong-Gu; CREED, W. E. Douglas. Institutional contradictions, praxis, and institutional change: a dialectical perspective. Academy of Management Review, v.27, n.2, p.222-247, 2002. http://dx.doi.org/10.5465/AMR.2002.6588004

SVENNINGSEN, Virginie; BOXENBAUM, Eva; RAVASI, Davide. How individuals cope with institutional complexity in organizations: a case study in the energy transition. In: EGOS COLLOQUIUM, 32, Naples, Italy, July, 2016. Anais..., 2016.

TOLBERT, Pamela S.; ZUCKER, Lynne G. A institucionalização da teoria institucional. In: CLEGG, S. R.; HARDY, C.; NORD, W. R. Handbook de Estudos Organizacionais, São Paulo, v. 1, p. 196-219, 1999.

VICENTE, Célia Silva; MAJOR, Maria João; PINTO, José Castro. Estudo da mudança nas práticas de controlo de gestão em Portugal. Contabilidade e Gestão, n. 10, p. 9-40, mar. 2011. 
WANDERLEY, Claudio de Araújo; SOEIRO, Tiago de Moura. Contradição institucional e o Balanced Scorecard: Um caso de mudança sem sucesso. Revista Universo Contábil. FURB, Blumenau, v. 12, n. 1, p. 45-65, jan./mar. 2016. http://dx.doi.org/10.4270/ruc.2016103

WEBSTER, Jane; WATSON, Richard T. Analyzing the past to prepare for the future: Writing a literature review. MIS Quarterly. v. 26, n. 2, p. 13-23, jun. 2002.

YIN, Robert K. Estudo de caso: planejamento e métodos. 5.ed. Porto Alegre: Bookman, 2015.

ZILBER, Tammar B. Institutionalization as an interplay between actions, meanings, and actors: the case of a rape crisis center in Israel. Academy of Management Journal, v. 45, n. 1, p. 234254, 2002. https://doi.org/10.5465/3069294

ZONI, Laura; DOSSI, Andrea; MORELLI, Marco. Management accounting system (MAS) change: field evidence. Asia-Pacific Journal of Accounting \& Economics, v. 19, n. 1, p. 119138, Apr. 2012. https://doi.org/10.1080/16081625.2012.668062

ZUCKER, Lynne G. Institutional patterns and organizations: culture and environment. Cambridge, Mass: Ballinger, 1988.

\section{APÊNCIDE - ROTEIRO DE ENTREVISTA}

\begin{tabular}{|c|c|}
\hline Questões & Entrevistado(s) \\
\hline $\begin{array}{l}\text { Caracterização do respondente e da empresa: } \\
\text { 1. Há quanto tempo está na empresa? } \\
\text { 2. Qual a função desempenhada e há quanto tempo está nesta função? } \\
\text { 3. Qual a sua formação? } \\
\text { 4. Qual é a estrutura da empresa? (possui setores definidos, divisões, } \\
\text { departamentos) } \\
\text { 5. Quem participa na tomada de decisões? }\end{array}$ & $\begin{array}{l}\text { Sócio proprietário; } \\
\text { Profissionais que atuam no nível } \\
\text { gerencial da empresa }\end{array}$ \\
\hline $\begin{array}{l}\text { 6. Fale um pouco sobre a história da empresa desde o início (seu } \\
\text { desenvolvimento, situações importantes que marcaram sua trajetória) }\end{array}$ & \multirow{2}{*}{ Sócio proprietário; } \\
\hline 7. Quantos funcionários a empresa tem hoje? & \\
\hline $\begin{array}{l}\text { 8. Dentre os controles existentes na empresa, escolha um que considere ter } \\
\text { sido adotado com sucesso e informe há quanto tempo ele está em uso. } \\
\text { Houve alguma situação em que a empresa tentou implementar algum } \\
\text { controle de gestão e não conseguiu? }\end{array}$ & \multirow{7}{*}{$\begin{array}{l}\text { Sócio proprietário; } \\
\text { Profissionais que atuam no nível } \\
\text { gerencial da empresa }\end{array}$} \\
\hline $\begin{array}{l}\text { 9. Como surgiu a necessidade de adotar as ferramentas de controle de } \\
\text { gestão que a empresa tem hoje? Quem teve a ideia, quem buscou } \\
\text { informações e auxiliou na sua adoção? }\end{array}$ & \\
\hline $\begin{array}{l}\text { 10. Antes de adotar esta ferramenta de gestão, como era realizado o } \\
\text { controle na empresa? }\end{array}$ & \\
\hline $\begin{array}{l}\text { 11. Quais foram as principais dificuldades encontradas na adoção desta } \\
\text { ferramenta? }\end{array}$ & \\
\hline $\begin{array}{l}\text { 12. Como a empresa decide pela adoção de uma nova ferramenta de } \\
\text { controle de gestão? (quais os envolvidos neste processo?) }\end{array}$ & \\
\hline $\begin{array}{l}\text { 13. Comente como foi a aceitação desta ferramenta de controle entre os } \\
\text { membros da empresa. (acreditavam que iria gerar benefícios ou mais } \\
\text { dificuldade nas atividades diárias? Quais?) Ou simplesmente aceitaram } \\
\text { sem questionamentos? }\end{array}$ & \\
\hline $\begin{array}{l}\text { 14. A empresa utiliza um "manual" com as regras que normatizam este } \\
\text { controle? (quando deve ser feito, como deve ser feito...) Em caso } \\
\text { afirmativo, como o mesmo auxilia no uso de tal ferramenta? Em caso } \\
\text { negativo, qual o motivo para não o elaborar? }\end{array}$ & \\
\hline
\end{tabular}


Institucionalização de novas práticas de controles de gestão: forças que potencializam ou comprometem o processo nos pequenos empreendimentos

\begin{tabular}{|c|c|}
\hline Questões & Entrevistado(s) \\
\hline $\begin{array}{l}\text { 15. A adoção desta ferramenta alterou as rotinas diárias? (a forma habitual } \\
\text { de fazer aquela atividade?) De que maneira? }\end{array}$ & \multirow{7}{*}{$\begin{array}{l}\text { Sócio proprietário; } \\
\text { Profissionais que atuam no nível } \\
\text { gerencial da empresa }\end{array}$} \\
\hline $\begin{array}{l}\text { 16. É possível perceber que esta ferramenta já está consolidada? (faz parte } \\
\text { das ações diárias da empresa?) De que forma? }\end{array}$ & \\
\hline $\begin{array}{l}\text { 17. Houve algum tipo de pressão externa para que a empresa adotasse esta } \\
\text { ferramenta de controle de gestão? (legislação, mercado, tecnologia) }\end{array}$ & \\
\hline $\begin{array}{l}\text { 18. E internamente, houve a solicitação de um grupo específico para } \\
\text { adoção desta ferramenta de controle gerencial? }\end{array}$ & \\
\hline $\begin{array}{l}\text { 19. A empresa busca comunicar-se com outras organizações do mesmo } \\
\text { setor para trocar experiências em relação a problemas comuns? De que } \\
\text { forma isso ocorre? }\end{array}$ & \\
\hline $\begin{array}{l}\text { 20. Houve resistência de indivíduos ou de grupos em relação à adoção } \\
\text { desta ferramenta? Qual o motivo? }\end{array}$ & \\
\hline $\begin{array}{l}\text { 21. Na empresa, existem grupos que defendem esta ferramenta de controle } \\
\text { de gestão? Como eles fazem isto? }\end{array}$ & \\
\hline
\end{tabular}

